\title{
NOVOS \\ ELEMENTOS \\ PARA A \\ PERIODIZAÇÃO \\ DO PORTUGUÊS \\ NO BRASIL ${ }^{1}$
}

\section{NUEVOS ELEMENTOS PARA LA PERIODIZACIÓN DEL PORTUGUÉS EN BRASIL}

\author{
NEW ELEMENTS ON THE PERIODIZATION OF PORTUGUESE IN BRAZIL
}

Williane Silva Corôa*

Universidade do Estado da Bahia

RESUMO: O objetivo principal neste artigo é apresentar novos elementos sobre as origens do Português Brasileiro (PB). Situamonos no campo disciplinar da Sintaxe diacrônica, na perspectiva gerativista, e analisamos a sintaxe da colocação de clíticos, em cartas escritas por brasileiros ao longo do século XVII com fins de oferecer novos elementos sobre a periodização do português no Brasil. Nessa direção, apresentamos evidências de que a escrita brasileira ao longo do século XVII reflete propriedades do Português Clássico (PCl), considerada "a língua das caravelas", por Galves (2007), mas já apontam para inovações sintáticas que são idiossincráticas da gramática do Português Brasileiro (PB). Esses resultados parecem validar a hipótese defendida por Ribeiro (1998) e Galves (2007) de que as origens do PB são anteriores ao século XIX e podem auxiliar a repensar a periodização da língua portuguesa no Brasil.

PALAVRAS-CHAVE: Português Clássico. Origens do Português Brasileiro. Periodização. Clíticos.

RESUMEN: El objetivo principal en este artículo es presentar nuevos elementos sobre los orígenes del Portugués Brasileño (PB). Nos situamos en el campo disciplinar de la Sintaxis diacrónica, en una perspectiva generativista, y analizamos la sintaxis de la colocación de clíticos, en cartas escritas por brasileños durante el siglo XVII, con el fin de ofrecer nuevos elementos sobre la periodización del portugués en Brasil. En esa dirección, presentamos evidencias de que la escritura brasileña a lo largo del siglo XVII refleja propiedades del Portugués Clásico (PCl), considerada "la lengua de las carabelas" por Galves (2007), pero ya apunta para innovaciones sintácticas que son idiosincráticas de la gramática del Portugués Brasileño (PB). Esos resultados parecen validar la hipótesis defendida por Ribeiro (1998) y Galves (2007) de que los orígenes del PB son anteriores al siglo XIX y pueden ayudarnos a repensar la periodización de la lengua portuguesa en Brasil.

PALABRAS CLAVE: Portugués Clásico. Orígenes del Portugués Brasileño. Periodización. Clíticos.

\footnotetext{
${ }^{1}$ Esta pesquisa é realizada com o auxílio da Fundação de Amparo à Pesquisa do Estado de São Paulo (FAPESP), Processo 2017/16581-3.

* Doutoranda do Programa de Pós-graduação em Linguística (IEL/UNiCAMP). Professora da Universidade do Estado da Bahia, CampusXXI. E-mail:wcoroa@uneb.br.
} 
ABSTRACT: The main objective of this article is to present new elements on the origins of Brazilian Portuguese (BP). We situate ourselves in the disciplinary field of diachronic syntax, from a generative perspective, and we analyze the syntax of clitic placement in letters written by Brazilians throughout the 17th century in order to offer new elements about the periodization of Portuguese in Brazil. In this sense, we present evidence that Brazilian writing throughout the 17 th century reflects properties of Classic Portuguese (CIP), considered "the language of the caravels", by Galves (2007), but already points to syntactic innovations that are idiosyncratic in the grammar of Brazilian Portuguese (BP). These results seem to validate the hypothesis defended by Ribeiro (1998) and Galves (2007) that the origins of BP are prior to the 19th century and can help to rethink the periodization of the Portuguese language in Brazil.

KEYWORDS: Classical Portuguese. Origins of Brazilian Portuguese. Periodization. Clitics.

\section{CONSIDERAÇÕES INICIAIS}

Neste artigo, apresentamos novos elementos para discutir as origens do Português Brasileiro (PB). A periodização da história da língua portuguesa no Brasil, apesar de contar com inúmeras propostas, raramente leva em consideração aspectos sintáticos. Por isso, partindo de um corpus constituído por Cartas da Câmara Municipal de Salvador, produzidas por brasileiros que ocupavam o cargo de escrivão ao longo dos séculos XVII, analisamos os padrões de colocação de clíticos e levantamos a hipótese, seguindo Ribeiro (1998) e Galves (2007), de que as origens do PB são anteriores ao século XIX, pois o padrão de colocação de clíticos apresentados nesses textos já reflete características da gramática do $\mathrm{PB}$.

O corpus analisado é composto por 283 cartas escritas ao Rei por 07 escrivães brasileiros, ao longo do século XVII, que totalizam 120.049 palavras e 2.592 sentenças. Por seu caráter idiossincrático, o corpus explorado pode trazer uma visão original e relevante sobre o estudo da emergência de uma gramática brasileira e pode nos ajudar a revelar, a partir de uma fonte de dados inexplorada e potencialmente muito rica, os processos de diferenciação entre as variedades do português.

O artigo é organizado em quatro seções: a primeira traz, de modo resumido, as propostas de periodização para a história da língua portuguesa no Brasil e aponta para o fato de que os aspectos sintáticos, marcadamente onde o PB e o Português Europeu (PE) diferem mais fortemente, assim como o período em que a gramática do PB surge, não estão presentes nas propostas elencadas².

Na segunda seção, trazemos os referenciais teórico-metodológicos que embasam nossa análise sobre a sintaxe de colocação de clítico. A análise adotada, seguindo a Teoria Gerativa, é a de Galves, Torres Morais e Ribeiro (2005). Na terceira seção, apresentamos os resultados da análise e realizamos uma breve comparação com outras análises presentes na literatura. Na quarta seção, analisamos o que esses resultados podem "revelar" sobre as origens do PB. E, por fim, apresentamos as considerações finais.

\section{A HISTÓRIA DA LÍNgUA PORTUGUESA NO BRASIL: PROPOSTAS DE PERIODIZAÇÃO E ASPECTOS INTRALINGUÍSTICOS}

Inúmeras são as propostas de periodização para a língua falada no Brasil. A maioria considera não só aspectos linguísticos, mas, sobretudo, aspectos sócio-históricos para determinar o percurso da língua portuguesa no Brasil. Aqui, apresentaremos, de modo bastante resumido, as propostas de Silva Neto, Marlos Pessoa de Barros, Tania Lobo, Volker Noll e Dante Lucchesi.

A proposta de Silva Neto (1986) divide a história da língua portuguesa no Brasil em três fases: a primeira do início da colonização (1532) até a expulsão dos holandeses (1654); a segunda, começa em 1654 e vai até 1808 com a chegada do Príncipe Regente e da Corte portuguesa ao Brasil; e a terceira fase, a partir de 1808 é marcada pela chegada da Corte portuguesa ao Rio de Janeiro - evento que transformou profundamente a vida na colônia.

${ }^{2}$ Apresentamos os estudos de Tarallo (1993), Ribeiro (1998) e Galves (2007), que interpretaram as mudanças pelas quais o português passou a partir de diferentes fenômenos sintáticos. 
A proposta de periodização de Marlos de Barros Pessoa (2003) também estabelece três fases: a primeira (1534-1750), em que imperam o multilinguismo e a formação de variedades linguísticas rurais; a segunda fase (1750-1922), em que ocorre a koineização de diferentes variedades e a "formação do português comum brasileiro"; e a terceira fase (1922-) correspondente ao período de elaboração da língua literária.

Já a proposta de Lobo (2003) fundamenta-se na história demográfico-linguística brasileira, no crescimento populacional associado ao processo de urbanização do país e no processo de escolarização associado ao processo de estandardização linguística. Ao correlacionar tais fatos, Lobo (2003) propõe duas grandes fases: a primeira, na qual prevalece o multilinguismo generalizado, caracterizado pela não-urbanização, não-escolarização e não-estandardização linguística; e a segunda fase, em que prevalece o multilinguismo localizado, fruto da escolarização, da urbanização e da estandardização linguística.

Como as propostas anteriormente apresentadas se limitam quase exclusivamente a fatos históricos, Noll (2008) sugere uma periodização pautando-se, sobretudo, em critérios linguísticos. A periodização de Noll (2008) divide-se cinco fases: (1) de 1500 a 1550, fase inicial, em que a língua portuguesa é trasladada para o Brasil; (2) de 1550 a 1700, primeira fase, em que é possível ver a formação das primeiras características da língua portuguesa no Brasil; (3) de 1700 a 1800, fase diferenciadora, em que a diferenciação das variedades europeia e brasileira começa a aparecer; de (4) 1800 a 1950, fase de desenvolvimento da escrita e do ensino assinalada pela introdução da imprensa tipográfica, pela implantação do ensino público oficial e a criação do ensino superior e pela diferenciação progressiva da norma europeia; e, (5) de 1950 em diante, fase de nivelação, marcada pela evolução dos meios de comunicação, pela introdução da televisão e a urbanização progressiva.

Por fim, tem-se a proposta de Lucchesi (2017), considerada inovadora por levar em consideração um conjunto mais amplo de línguas presentes na formação da sociedade brasileira, recuando temporalmente para o período anterior à colonização. Lucchesi (2017) propõe quatro fases: a primeira, denominada de Tupinização da Costa, se inicia após o ano mil, com a expansão tupi pelo litoral, e se encerra no ano de 1532, com o efetivo início da colonização do Brasil pelos portugueses; a segunda fase, o Multilinguismo generalizado, se estende de 1532 a 1695, e é caracterizada pela baixa densidade demográfica e pelo plurilinguismo; a terceira fase, a Homogeneização Linguística, inicia-se em 1695, com a descoberta do ouro em Minas Gerais, e se estende até a Revolução de 1930; a quarta fase, chamada de Nivelamento linguístico, de 1930 aos dias atuais, é marcada pela crescente industrialização e urbanização do país, pela difusão da norma urbana culta, apagando as marcas do contato na norma popular.

É importante ressaltar que, apesar de as diversas propostas aqui elencadas considerarem tanto a história externa quanto a história interna da língua (i) nenhuma examina aspectos sintáticos, onde o PB e o PE diferem mais fortemente e (ii) nenhuma aponta para o momento em que a vertente da língua portuguesa identificada como PB emergiu. Contudo, há estudos que, apesar de não proporem uma periodização para o $\mathrm{PB}$, buscam responder às questões (i) e (ii).

Um dos primeiros a investigar as origens do PB, a partir de dados linguísticos foi Fernando Tarallo. Em Diagnosticando uma gramática brasileira: o português d'aquém e d'além mar ao final do século XIX, Tarallo (1996) esboça a emergência de uma gramática brasileira, analisando quatro grandes mudanças sintáticas: a reorganização do sistema pronominal; a mudança nas estratégias de relativização; a reorganização dos padrões sentenciais básicos; e, a mudança dos padrões sentenciais em perguntas diretas e indiretas. Ao investigar os quatro casos anteriormente citados, Tarallo (1996) situa a emergência do português brasileiro no final do século XIX.

Seguindo as indagações levantadas por Tarallo (1996) sobre a emergência do PB, Ribeiro (1998), em A mudança sintática do português brasileiro é mudança em relação a que gramática?, defende que possivelmente houve uma mudança no PB na virada do século XVIII para o XIX, mas que muitos dos fatos analisados como resultantes de uma mudança do PB no século XIX se originaram no século XVI. Propõe, portanto, que o português implantado no Brasil é constituído de, pelo menos, duas gramáticas diferentes: a dos séculos XVI-XVIII e a dos séculos XIX-XX.

Além de apontar evidências externas tais como a Reforma Pombalina e a chegada da família real no Brasil, Ribeiro (1998) assinala algumas evidências internas à língua, como, por exemplo, a variação próclise-ênclise, o alçamento de clítico e a interpolação de 
diferentes tipos de constituintes. Diante disso, Ribeiro (1998) conclui que não se pode tomar o PE como parâmetro para o estudo da mudança gramatical do PB e que é necessário voltarmos nosso olhar para as gramáticas dos séculos XVI-XVIII e a dos séculos XIX-XX a fim de responder à questão: em relação a que sistema linguístico o PB mudou?

Galves (2007) retoma o questionamento de Ribeiro (1998) e, a partir do estudo sistemático da colocação de clíticos na história do português, defende, além de uma nova periodização para o PE, que a língua das caravelas - ou seja, aquela trazida pelos portugueses ao Brasil - corresponde ao que a autora chama de português médio ${ }^{3}$ - fase gramatical intermediária entre o português arcaico e o português moderno. Seguindo essa lógica, o PB teria evoluído a partir de uma única gramática, a gramática do português médio. Logo, conclui, baseando-se em diversas evidências empíricas, que a mudança ocorrida em Portugal, no século XVIII, não afeta a gramática do PB desenvolvida no Brasil, a não ser em nível superficial ${ }^{4}$.

\begin{tabular}{|c|c|c|c|}
\hline & TARALLO & RIBEIRO & GALVES \\
\hline $\begin{array}{l}\frac{\pi}{\pi} \\
\frac{\pi}{0} \\
ٍ \\
0\end{array}$ & $\begin{array}{c}\text { PB emerge no final do século } \\
\text { XIX. }\end{array}$ & $\begin{array}{l}\text { É possível que o PB tenha emergido na } \\
\text { virada do século XVIII para o XIX. }\end{array}$ & $\begin{array}{c}\text { Gramática que deu origem ao PB seria o } \\
\text { PCl. }\end{array}$ \\
\hline
\end{tabular}

Quadro 1: Resumos das propostas sobre as origens do PB considerando aspectos intralinguísticos

Fonte: elaborado pelo autor

Os trabalhos listados interpretaram as mudanças pelas quais o português passou, tomando diferentes fenômenos sintáticos e diferentes séculos como marcos definidores da gênese do PB. Neste artigo, adotamos a perspectiva de Ribeiro (1998) e Galves (2007) que situam as origens do PB anteriores ao século XIX e buscamos testar a hipótese de Galves (2007) de que a origem do PB é anterior ao século XIX e se origina a partir do Português Clássico (PCl), assim como de que a gramática que desembarcou no Brasil, "a língua das caravelas" é o PCl.

\section{A SINTAXE DA COLOCAÇÃO DE CLÍTICOS: PCl, PE e PB}

A colocação de clíticos é, sem dúvidas, um dos fenômenos mais intrigantes e estudados na história do português. Do ponto de vista sincrônico, o PB e o PE se distinguem bastante nesse aspecto. O PE apresenta um padrão bastante específico, diferindo dos padrões de colocação da maioria das línguas românicas; isto é, o padrão de colocação de clíticos do PE é majoritariamente enclítico, apesar de apresentar alguns contextos de variação. Já, o PB apresenta um sistema de colocação de clíticos bastante simples, com próclise generalizada.

Partindo do pressuposto de que tanto o PB quanto o PE têm sua origem no PCl, vamos observar os padrões de colocação de clíticos no PCl. De acordo com diferentes estudos (PAIXÃO DE SOUSA, 2004; GALVES; BRITTO; PAIXÃO DE SOUSA, 2005; GALVES; PAIXÃO DE SOUSA, 2017), o PCl é muito mais proclítico do que o PE moderno. No PCl, a próclise ocorre obrigatoriamente quando o verbo é precedido por partículas de foco, operadores afetivos e alguns advérbios (GALVES; BRITTO; PAIXÃO DE SOUSA, 2005).

\footnotetext{
${ }^{3}$ De acordo com Galves (2007), o português médio corresponde a uma gramática que emerge entre os séculos XIV e XV, e cujas características são progressivamente reveladas pelos textos escritos até os inícios do século XVI. Nesse ponto de vista, o português clássico passa a ser uma subdivisão do português médio.

${ }^{4}$ Cf. o trabalho de Pagotto (1992) sobre a influência da chegada da Corte portuguesa sobre a norma linguística brasileira; e Carneiro (2005) e M. A. Martins (2010) sobre o processo de competição de gramáticas.
} 
(1) Próclise categórica:

Bem me importava entender ao certo o que se passa ... (Melo, 1608)

Muito vos desejei cá ontem para ouvirdes explicar a Ene êste retrato. (Melo, 1608)

(GALVES; BRITTO; PAIXÃO DE SOUSA, 2005, p. 43).

Esses mesmos contextos se mantêm até hoje no PE em que a próclise é obrigatória quando quantificadores, marcadores de foco, marcadores de ênfase, advérbios focalizados, constituintes não-adverbiais focalizados e interrogativas e exclamativas QU- precedem o verbo (A. M. MARTINS, 2016).

Já a ênclise, no PCl, é categórica quando o verbo está em primeira posição. Esse contexto deriva da Lei Tobler-Mussafia. De acordo com essa Lei, os clíticos não podem aparecer na primeira posição de uma oração, uma vez que devem estar adjacentes ao verbo (BENINCÀ, 2004).

\section{Enclise categórica}

Defendeu-o, emparou-o (bem sabe Vossa Paternidade a história) e como verdadeiro amigo escreveu-lhe...(Sousa, 1556)

(GALVES; BRITTO; PAIXÃO DE SOUSA, 2005, p. 43).

No PE, a ênclise também é categórica com o verbo na primeira posição, além de sê-lo em sentenças com tópicos, adjuntos e sujeitos referenciais. Esses ambientes (sentenças com tópicos, adjuntos e sujeitos referenciais) eram contextos de variação no PCl.

No $\mathrm{PCl}$, a variação ocorria ou quando o complexo verbo-clítico era precedido por sintagmas preposicionados, advérbios, ou sujeitos referenciais não-focalizados (contexto de variação I, segundo Galves, Britto e Paixão de Sousa (2005)) ou quando o complexo verboclítico era precedido ou por uma oração dependente fronteada ou por uma conjunção coordenativa (contexto de variação II, segundo Galves, Britto e Paixão de Sousa (2005)).

\section{CONTEXTO DE VARIAÇÃO I}

Sujeito-V

Eu corro-me de dizer o que padeço (Melo, 1608)

Ele me disse que pasmava como lhe abastava o que tinha (Sousa, 1554)

\author{
Advérbio-V \\ Depois sucedeo-lhe o Mirão, seu sobrinho, ... (Couto, \\ 1542) \\ Hoje me parto. (A. Chagas, 1631)

\section{PP-V} \\ Em troca disto, ofereço-lhe da parte de Inglaterra \\ defesa de tôdas as suas colónias e ... (Alorna, 1750). \\ Com este aviso lhe foi juntamente infundida notícia \\ dos excessos que entre estas duas súbditas suas \\ passavam. (Bernardes, 1644)
}

(GALVES; BRITTO; PAIXÃO DE SOUSA, 2005, p. 42-43).

\section{CONTEXTO DE VARIAÇÃO II}

Orações segunda coordenadas

Achou-os ditosamente, falou-lhes, e rendeu-os a largarem aquela vida brutal, e virem a ser filhos da Igreja, e vassalos do Império Português. (A. Barros, 1675).

Durando as persuasões do padre, chegou preparada uma mezinha, e lhe pediram se retirasse. (Bernardes, 1644)

\section{Orações dependentes}

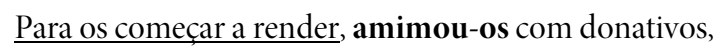
língua a todas as Nações não menos inteligível, que grata. (A. Barros, 1675).

Vendo-o um Cónego no adro daquela antiga Sé lhe disse: De quem sois meu menino? (A. Barros, 1675)

De acordo com Galves, Britto e Paixão de Sousa (2005), até o final do século XVII, a taxa de ênclise em contexto de variação I era inferior a 15\%. A partir do início do século XVIII, há um aumento gradativo no percentual de utilização da ênclise, que cresce 
exponencialmente atingindo o percentual de até 85\% no século XIX. Portanto, nos séculos XVI e XVII, a próclise é a opção preferida em contexto de variação I, o que deixa de ocorrer a partir do século XVIII, quando a ênclise passa a ser a opção mais usada.

Com relação ao contexto de variação II, Galves, Britto e Paixão de Sousa (2005) apontam que, no PCl, a ênclise é muito mais frequente do que a próclise. Nesse contexto, desde o início do século XVI, há uma taxa bastante alta de ênclise, tanto em sentenças com o fronteamento de uma oração dependente quanto com sentenças segunda coordenadas com a conjunção coordenativa.

Muitas análises foram propostas para dar conta do comportamento do clítico no PE, no PB e também no PCl. A proposta adotada aqui é a de Galves, Torres Morais e Ribeiro (2005) e está no âmbito da Gramática Gerativa. Segundo Galves, Torres Morais e Ribeiro (2005), o comportamento dos clíticos difere no PE, no PB e no PCl devido à interação de duas propriedades: (a) a categoria à qual os clíticos se ligam sintaticamente e (b) o requisito fonológico que força os clíticos a estarem em uma posição inicial com relação a alguma fronteira. Nessa perspectiva, o fenômeno de colocação de clíticos é, ao mesmo tempo, fonológico, morfológico e sintático.

É fonológico, pois o PE possui acentuação ao nível da palavra prosódica, como apontam Andrade e Laks (1992) e Frota e Vigário (2001). Isso explica por que a prosódia proíbe os clíticos em posição pré-verbal independentemente da posição do verbo em relação aos limites da oração. É morfológico, pois segundo Galves, Torres Morais e Ribeiro (2005) os clíticos comportam-se como afixos e estão sujeitos às regras de formação de palavras. É sintático, porque o lugar de realização do clítico é definido sintaticamente (KAYNE, 1991; RAPOSO, 2000).

De acordo com Galves, Torres Morais e Ribeiro (2005), seguindo Galves e Sândalo (2004), a colocação de clíticos no PE, no PB e no PCl também é resultado da interação de duas restrições: a restrição de borda e a restrição não inicial.

(3) Restrição de borda: um clítico está alinhado à borda esquerda de I-barra.

(4) Restrição não inicial: um clítico não pode ser o primeiro elemento do primeiro X-barra da oração.

A restrição de borda diz que o clítico deve sempre estar alinhado à esquerda de I-barra. A noção de restrição de borda adotada por Galves e Sandâlo remete a Prince e Smolensky (1993) que definem as noções de prefixo e sufixo como morfemas sujeitos a restrições que alinham as bordas dos morfemas com as bordas da palavra. Se a restrição de borda estiver ativa na morfologia de uma dada língua, o clítico será realizado como um sufixo.

Já, a restrição não inicial $^{5}$ define a posição em que o elemento não acentuado não pode ocorrer e articula questões sintáticas e prosódicas, uma vez que o componente sintático define o local de realização do clítico (I-barra) e o componente prosódico define o domínio em que o clítico não pode ser o elemento inicial (X-barra).

De que modo, então, as duas restrições interagem para explicar a colocação de clíticos no PCl, no PE e no PB? Segundo Galves, Torres Morais e Ribeiro (2005), a próclise ou a ênclise seriam derivadas a depender se uma das restrições está ativa na língua. A restrição de borda, por default, garante a ocorrência da próclise. Quando a restrição não inicial está ativa, a restrição de borda é violada, gerando a ênclise.

Tanto no PCl quanto no PE, a restrição não inicial está ativa e por isso a próclise não ocorre em sentenças V1 absolutas. Essa restrição, porém, difere no modo como é implementada nessas línguas. No PCl, ela é aplicada a um constituinte X pré-verbal desde que X esteja em uma posição externa à oração. No PE, ela se aplica não ao primeiro constituinte $\mathrm{X}$, mas sim ao primeiro X-barra da sentença, o que explica a ocorrência de ênclise em contextos de variação no PCl. Desse modo, no PCl, a restrição não inicial é aplicada no domínio prosódico; no PE, no domínio sintático. No PB, a restrição não inicial não está mais ativa, restando a restrição de borda o que explica a próclise generalizada.

Para ilustrar melhor esse fenômeno, neste artigo, analisamos a colocação de clíticos no conjunto de Cartas e Atas da Câmara

${ }^{5}$ Esta restrição correlaciona-se com a Lei Tobler-Mussafia. 
Municipal de Salvador com o intuito de verificar se nos textos escritos por brasileiros dessa época os contextos de colocação de clíticos se mantêm e se já há indícios da emergência de uma gramática brasileira, ou seja, se nesses textos já é possível verificar se a restrição não inicial ainda está ativa.

\section{O PORTUGUÊS ESCRITO NO BRASIL NO SÉCULO XVII: ANÁLISES PRELIMINARES}

É bem sabido que a gramática brasileira se caracteriza como proclítica, ou seja, a próclise é generalizada em diferentes contextos sintáticos. Como apontado por Paixão de Sousa (2004), Galves, Britto e Paixão de Sousa (2005), entre outros. A gramática do PCl também é bastante proclítica, apresentando alguns contextos de variação próclise versus ênclise e apresentando restrição de próclise em contextos V1.

Partindo dos contextos de variação próclise x ênclise delineados por Galves, Britto e Paixão de Sousa (2005) e buscando observar se há evidências que apontem para a emergência de padrões de colocação de clíticos associados à gramática do PB, analisamos um conjunto de cartas escritas por "Homens Bons", a longo do século XVII, membros da Câmara Municipal de Salvador, nascidos no Brasil $^{6}$.

Os contextos sintáticos analisados foram: contextos de variação I, contextos de variação II, sentenças com verbos em primeira posição absoluta. No caso dos contextos de variação I e II, buscamos identificar se, no corpus analisado, os padrões da variação próclise $\mathrm{x}$ ênclise apresentam o mesmo comportamento encontrado por Galves, Britto e Paixão de Sousa (2005). Já, nas sentenças com verbos em primeira posição absoluta, buscamos identificar padrões que reflitam a gramática do PB.

\subsection{CONTEXTO DE VARIAÇÃO I}

Como vimos anteriormente, o contexto de variação I é aquele em que o complexo verbo-clítico precede sintagmas preposicionados, advérbios, ou sujeitos referenciais não-focalizados (GALVES; BRITTO; PAIXÃO DE SOUSA, 2005). Nos nossos dados, encontramos 50 ocorrências: 48 de próclise e 02 de ênclise.

\begin{tabular}{c|c|c} 
Ênclise & Próclise & TOTAL \\
\hline $2 / 50(4 \%)$ & $48 / 50(96 \%)$ & $50 / 50(100 \%)$
\end{tabular}

Tabela 1: Próclise versus ênclise no contexto de variação I

Fonte: elaborado pelo autor

Abaixo, reproduzimos algumas ocorrências em contexto de variação I no corpus analisado:

\section{Sujeito-V}

(5) Vossa Mercê nos faça mercê remeter-lha, e fazer com ele a queira aceitar, e procurar com todo o cuidado, e zelo o conseguimento de nossas pretensões, e requerimentos (va_Aragão, 1630).

\section{PP-V}

(6) [Sobre a queixa dos povos das vilas do Camamú e Boipeba, e Cairú] se responde ((va_Carneiro Filho, 1670).

\footnotetext{
${ }^{6}$ A metodologia de análise dos dados segue os moldes adotados pelos membros do Projeto CorPorA II: um corpus anotado para a história do português brasileiro, coordenado pela Profa. Dra. Charlotte Marie Chambelland Galves, IEL, Unicamp.
} 


\section{ADV}

(7) [agora] se intromete também a medir os prédios urbanos dentro da cidade para o que tem mandado notificar a muitos moradores que apresentem os títulos dos chãos em que têm casas (va_Vasconcelos, 1672).

\begin{tabular}{c|c|c|c} 
& Ênclise & Próclise & TOTAL \\
\hline Sujeito-V & $0 / 18(0 \%)$ & $18 / 18(100 \%)$ & $18 / 50(32 \%)$ \\
\hline PP-V & $0 / 26(0 \%)$ & $26 / 26(100 \%)$ & $26 / 50(60 \%)$ \\
\hline ADVP-V & $2 / 6(40 \%)$ & $4 / 6(60 \%)$ & $6 / 50(8 \%)$
\end{tabular}

Tabela 2: Próclise versus ênclise no contexto de variação I por tipo de sintagma

Fonte: elaborado pelo autor

De um modo geral, os resultados encontrados vão ao encontro daqueles descritos na literatura. De acordo com Galves, Britto e Paixão de Sousa (2005), no PCl, no contexto de variação $I$, a próclise é uma opção neutra e a ênclise é uma opção marcada, correspondendo a distintas estruturas, estando sujeitas a condicionamentos estilísticos e textuais. A prevalência da próclise entre os séculos XVI e XIX também é atestada em outros estudos, como em Pagotto (1992), Carneiro (2005), M. A. Martins (2010) e Cardoso (2020).

\subsection{CONTEXTO DE VARIAÇÃO II}

O contexto de variação II é aquele em que o complexo verbo-clítico ou é (i) precedido por uma oração dependente fronteada, ou é (ii) precedido por uma conjunção coordenativa. Com relação a (i), encontramos 96 ocorrências, todas proclíticas.

\begin{tabular}{c|c|c} 
Ênclise & Próclise & TOTAL \\
\hline $0 / 96(0 \%)$ & $96 / 96(100 \%)$ & $96 / 96(100 \%)$
\end{tabular}

Tabela 3: Próclise versus ênclise quando o complexo verbo-clítico é precedido por uma oração dependente Fonte: elaborado pelo autor

\section{Orações Dependentes}

(8) a. [quando o tempo der lugar em todo] nos terá Vossa Mercê muito a seu serviço (Aragão, 1630).

b. e [mandando Vossa Mercê certidão do dia em que acabou o exercício] lhe ajustaremos a conta pontualmente (Aragão, $\sim 1630)$.

Nos dados analisados, encontramos próclise categórica, um comportamento bastante diferente do que é reportado por Galves, Britto e Paixão de Sousa (2005), visto que nesse ambiente a ênclise é a opção preferida, com cerca de 42\%, no século XVII. Dos estudos já realizados sobre a colocação de clíticos em textos escritos por brasileiros, apenas os dados de Cardoso (2020) (100\% de próclise no século XVII) apresentam um comportamento semelhante aos encontrados no nosso estudo. Carneiro (2005) e M. A. Martins (2010), por exemplo, analisando dados do século XIX e XX, encontram os mesmos padrões reportados por Galves, Britto e Paixão de Sousa (2005). 
Quando o complexo clítico-verbo é precedido por uma (ii) conjunção coordenativa, encontramos 54 ocorrências, das quais 47 são de próclise e 07 de ênclise.

\begin{tabular}{c|c|c} 
Ênclise & Próclise & TOTAL \\
\hline $7 / 54(13 \%)$ & $47 / 54(87 \%)$ & $54 / 54(100 \%)$
\end{tabular}

Tabela 4: Próclise versus ênclise quando o complexo verbo-clítico é precedido por uma conjunção coordenativa em escrivães brasileiros e portugueses

Fonte: elaborado pelo autor

\section{Coordenadas}

(9) e a pedimos prostrados a seus reais pés (va_Aragão, 1630).

(10) e requerem-se-lhe abata a importância de suas fintas: (va_Vasconcelos, 1672).

Nesse ambiente, também encontramos um comportamento bastante diferente do que é reportado por Galves, Britto e Paixão de Sousa (2005), que encontraram cerca de 42\% de ênclise no século XVII. Os dados também diferem daqueles encontrados por Carneiro (2005) e M. A. Martins (2010) para o século XIX (cerca de 70\% de ênclise). Novamente, apenas Cardoso (2020) encontra uma distribuição mais próxima da que encontramos aqui, com $8 \%$ de ênclise.

\subsection{SENTENÇAS COM O VERBO EM PRIMEIRA POSIÇÃO ABSOLUTA}

Vimos que a ênclise, no PCl, é categórica quando o verbo está em primeira posição. O mesmo ocorre no PE. Uma das inovações da gramática do PB é a ocorrência de próclise em sentenças com verbo em primeira posição absoluta. Nos dados analisados, encontramos 18 casos de próclise em sentenças com o verbo em posição inicial e 17 casos de ênclise. Apresento, abaixo, o contexto de algumas das ocorrências.

\section{Ênclise}

(11) Concedemo-lo enquanto a avaria feita a requerimento das partes aos nossos donativos (va_Pinheiro, 1602).

(12) a. Anossaobrigação ao Serviço de Vossa Alteza, eade procurar obem Comum | desta Republiqua da B[ahi]a [s:syn-clause] nos leva por esta aos Reaes Pés de V [ossa $] \mathrm{A}[$ lteza $]$ a Repre- | zentar o prejuizo q[ue] se seguem de sehirem fundando, e fazendo pella | terra dentro muitos Eng[enh] os deaSuc[are]S junto hus dos outros sem fun- | damento deterra bastante aoq[ue] demandão delenhas para oseu gasto que he muito grande (va_Aragão, 1630).

Contrastando os dados de próclise e ênclise em sentenças com o verbo em posição inicial, temos:

\begin{tabular}{l|c|c} 
Ênclise & Próclise & TOTAL \\
\hline $17 / 35(49 \%)$ & $18 / 35(51 \%)$ & $35 / 35(100 \%)$
\end{tabular}

Tabela 5: Variação próclise x ênclise em sentenças V1

Fonte: elaborado pelo autor

Em outros estudos sobre a diacronia do PB, a próclise em contexto V1 em textos brasileiros do século XIX é atestada em um percentual não tão alto quanto aquele que encontramos nos dados. Pagotto (1992), por exemplo, encontra 2 ocorrências de próclise 
em 8 dados $^{7}$ nos textos dos séculos XVI ao XVIII e nenhuma ocorrência em textos do século XIX. Já, Carneiro (2005) ${ }^{8}$ e M. A. Martins (2010), ao contrário de Pagotto (1992), encontram ocorrências de próclise em contexto V1 no século XIX, que totalizam cerca de $5 \%$ dos dados analisados em ambas as amostras.

Portanto, nos dados analisados, verificamos a generalização da próclise em ambiente de variação e o licenciamento da próclise em contextos de sentenças V1, o que parece antecipar uma característica do PB: a próclise generalizada.

\section{NOVOS ELEMENTOS PARA REPENSAR A PERIODIZAÇÃO DA LÍNGUA PORTUGUESA NO BRASIL}

Com base nos dados analisados, identificamos um padrão proclítico nos textos escritos por brasileiros ao longo do século XVII. Sabemos também que a gramática do $\mathrm{PCl}$ é bastante proclítica. De que modo, então, a análise apresentada contribui para repensarmos as propostas de periodização existentes?

Os dados oferecem evidências de que o padrão de colocação de clíticos nos textos analisados já apresenta diferenciação com relação à gramática clássica. A ocorrência de próclise em sentenças V1 - em um percentual maior do que os casos de ênclise - aponta que a gramática brasileira começa a emergir muito antes do século XIX.

Seguindo a análise de Galves, Torres Morais e Ribeiro (2005), encontramos evidências de que nos textos escritos por brasileiros ao longo do século XVII a restrição não inicial, ativa no PCl, começa a se perder. A restrição não inicial garantia que a ênclise em sentenças V1 fosse obrigatória nos textos clássicos. Isso significa que, apesar de apresentar semelhanças com a gramática clássica, $\mathrm{O}$ português escrito no Brasil por brasileiros ao longo do século XVII já deixa proeminente aspectos definidores da gramática do Português Brasileiro: a próclise generalizada.

Apesar de não ter registrado a próclise em contexto V1, Cyrino (1997) apresenta inúmeros exemplos de clíticos no início de sílabas métricas em poemas de Gregório de Mattos, o que a leva a pensar que a mudança na sintaxe dos clíticos já estava acontecendo no XVII.

Os dados analisados, somados às informações presentes em Cyrino (1997), indicam a necessidade de revisar as periodizações existentes, sobretudo porque as periodizações não levam em consideração aspectos sintáticos e nem indicam em que momento o PB emergiu. Os dados também corroboram a hipótese de Ribeiro (1998) e Galves (2007) de que a gramática que está na base do PB não é o PE. Portanto, o PB não muda em relação ao PE. Ou seja, desse ponto de vista, a mudança ocorrida em Portugal a partir do século XVIII não afeta a gramática desenvolvida no Brasil.

\section{CONSIDERAÇÕES FINAIS}

A partir da investigação de fatos empíricos relativos à sintaxe dos clíticos à luz da teoria gerativa, apontamos a necessidade de revisão das propostas de periodização para a língua portuguesa no Brasil. Os dados analisados apontam para um processo de diferenciação que começa já no século XVII. Como examinamos apenas dados do século XVII, não podemos afirmar nada sobre a sintaxe dos clíticos ao longo do século XVIII, mas sabemos, a partir de pesquisas já realizadas (Cf. Carneiro, 2005; M. A. Martins, 2010) que, ao longo do século XIX, há um intenso processo de competição de gramáticas (diglossia sintática), em que os padrões das gramáticas do $\mathrm{PCl}$, do PB e do PE são refletidos nos textos escritos por brasileiros.

\footnotetext{
${ }^{7}$ Destaca-se aqui que Pagotto (1992) não apresenta exemplos dos dados relativos ao século XVI nem ao XVIII.

${ }^{8} \mathrm{O}$ trabalho de Carneiro (2005) foi pioneiro em registrar próclise em contexto V1, uma característica da gramática do PB, nos escreventes nascidos no século XIX.
} 
Sabemos que são necessárias outras análises, inclusive análises de dados relativos ao século XVIII, que possam validar e/ou refutar os dados aqui apresentados. Por ora, deixamos a nossa contribuição sobre a necessidade de voltarmos nosso olhar sobre a sintaxe do período para que possamos melhor compreender quando a gramática brasileira emerge.

\section{REFERÊNCIAS}

ANDRADE, E. d'; LAKS, B. Na crista da onda: o acento de palavra em português. In:ENCONTRO DA ASSOCIAÇÃO PORTUGUESA DE LINGUÍSTICA, 7., 1992, Lisboa. Actas, Lisboa, 1992. p. 15-26.

BENINCÀ, P. The Left Periphery of Medieval Romance. Studi Linguistici E Filologici Online, v. 2, n. 2, p. 243-97, 2004.

CARDOSO, L. da S. A gramática dos pronomes clíticos no Brasil Colônia: o português clássico na história do português brasileiro. 2020. Dissertação (Mestrado em Estudos Linguísticos) - Programa de Pós-Graduação em Estudos Linguísticos, Universidade Estadual de Feira de Santana, Feira de Santana, 2020.

CARNEIRO, Z. de O. N. Cartas brasileiras (1809-1904): um estudo lingüístico-filológico. 2005. Tese (Doutorado em Linguística) Instituto de Estudos da Linguagem, Universidade Estadual de Campinas, Campinas, SP, 2005.

CYRINO, S. O objeto nulo no português brasileiro: um estudo sintático-diacrônico. Londrina: Editora da UEL, 1997.

FROTA, S.; VIGÁRIO, M. On the correlates of rhythmic distinctions: the European/Brazilian Portuguese case. Probus, n. 13, p. 247$273,2001$.

GALVES, C. A língua das caravelas: periodização do português europeu e origem do português brasileiro. In: CASTILHO, A. de; TORRES MORAIS, M. A.; LOPES, R.; CYRINO, S. (org.). Descrição, história e aquisição do português brasileiro. Campinas: Pontes, 2007.p. 513-528.

GALVES, C.; BRITTO, H.; PAIXÃO DE SOUSA, M. C. The change in clitic placement from Classical to Modern European Portuguese: results from the Tycho Brahe Corpus. Journal of Portuguese Linguistics, Lisboa, v. 4, n.1, p. 39-68, 2005.

GALVES, C.; PAIXÃO DE SOUSA, M. C. The change in the position of the verb in the history of Portuguese: Subject realization, clitic placement and prosody. Language, v. 93, n. 3, 2017, p. e158-e180.

GALVES, C.; TORRES MORAIS, M. A;; RIBEIRO, I. Syntax and Morphology in the placement of clitics in European and Brazilian Portuguese. Jornal of Portuguese Linguistics, Lisboa, v. 4, n. 2, p. 143-177, 2005.

GALVES, C.; SÂNDALO, F. Clitic-Placement in European Portuguese and Syntax-Phonology Interface. MIT Working Papers in Linguistics, n. 47, p. 115-128,

2004.

KAYNE, R. Romance clitics, verb movement and PRO. Linguistic Inquiry, n. 22, p. 647-686, 1991.

LOBO, T. A questão da periodização da história linguística do Brasil. In: CASTRO, I.; DUARTE, I. Razões e emoção: miscelânea de estudos em homenagem a Maria Helena Mateus. Lisboa: Imprensa Nacional - Casa da Moeda, 2003. p. 395-410.

LUCCHESI, D. A periodização da história sociolinguística do Brasil. DELTA [online], v. 33, n. 2, p. 347-382, 2017. Disponível em: http://dx.doi.org/10.1590/0102-445067529349614964. Acesso em: 20 maio 2018. 
MARTINS, A. M. A colocação dos pronomes clíticos em sincronia e diacronia. In: MARTINS, A. M.; CARRILHO, E. (org.). Manual de linguística portuguesa. Berlin/Boston: De Gruyter, 2016. p. 371-400.

MARTINS, M. A. Competição de gramáticas do português na escrita catarinense dos séculos 19 e 20. 2010. 326 f. Tese (Doutorado em Linguística) - Universidade Federal de Santa Catarina, Florianópolis, 2010.

NOLL, V. O português brasileiro: formação e contrastes. São Paulo: Globo, 2008.

PAGOTTO, E. A posição dos clíticos em Português: um estudo diacrônico. 1992. 168 f. Dissertação (Mestrado em Linguística) Instituto de Estudos da Linguagem, Universidade Estadual de Campinas, Campinas, SP, 1992.

PAIXÃO DE SOUSA, M. C. Língua barroca: sintaxe e história do português nos 1600. 2004. 455 f. Tese (Doutorado em Linguística) - Instituto de Estudos da Linguagem, Universidade Estadual de Campinas, Campinas, SP, 2004.

PESSOA, M. de B. Variação de uma variedade urbana e semi-oralidade: o caso do Recife, Brasil. Tübigen: Niemeyer, 2003.

PRINCE, A.; SMOLENSKY, P Optimality Theory: constraint interaction in generative grammar. Technical report \#2 of The Rutgers center for Cognitive Science. Rutgers University, 1993.

RAPOSO, E. Clitic Position and Verb Movement. In: COSTA, João. Portuguese Syntax: New Comparative Studies. Oxford: Oxford University Press. p. 266-297.

RIBEIRO, I. A mudança sintática do Português Brasileiro é uma mudança em relação a que gramática? In: CASTILHO, Ataliba T. de. (org.). Para a história do português brasileiro: primeiras ideias. v.1. São Paulo: Humanitas, 1998. p.101-119.

SILVA NETO, S. da. Introdução ao estudo da língua portuguesa no Brasil. 2 ed. Rio de Janeiro: INL, 1986[1951].

TARALLO, F. Diagnosticando uma gramática brasileira: o português d'aquém e d'além-mar ao final do século XIX. In: ROBERTS, I.; KATO, M. (org.) Português brasileiro: uma viagem diacrônica. 2. ed. Campinas: Editora da Unicamp: 1996. p. 69-106.

\section{()(1) $\circledast$}

Recebido em 24/01/2021. Aceito em 24/02/21. 